УДК 37

DOI $10.31483 / \mathrm{r}-22042$

\title{
И.Д. Минаева
}

\section{ОРГАНИЗАЦИЯ САМОСТОЯТЕЛЬНОЙ РАБОТЫ ПО АНГЛИЙСКОМУ ЯЗЫКУ СТУДЕНТОВ ЗАОЧНОЙ ФОРМЫ ОБУЧЕНИЯ В МОРСКОМ ВУЗЕ}

\begin{abstract}
Аннотация: в статье рассматриваются вопросы самостоятельной работы студентов заочного отделения неязыкового вуза и разные формы её организации в условиях модернизации образования. На обсуждение выносятся вопросы рациинального применения новых технологий в сочетании с традиционными методами обучения иностранному языку студентов заочной формы обучения. Цель применения новых технологий - повышение эффективности обучения в рамках компетентностного подхода в изучении английского языка в морском вузе при формировании компетенциий в соответствии с ФГОС ВПО и конвениячей ПДНВ78/95 ИМО.
\end{abstract}

Ключевые слова: организация самостоятельной работы, новые технологии, требования ФГОС ВПО и конвенцуии ПДНВ, интеграция общекультурных и профессиональных компетенций, дистанциионое обучение.

\section{I.D. Minaeva}

\section{ORGANIZATION OF ENGLISH SELF-STUDY OF PART-TIME MARITIME STUDENTS}

\begin{abstract}
: the paper considers the issues of part-time students' self-study and various ways of its organization in the terms of education modernization. The discussion concerns a reasonable application of new technologies together with traditional methods of teaching part-time students a foreign language. The aim of applying new technologies is enhancing the effectiveness of education with competence approach in marine English teaching in order to develop the competence in compliance with federal educational standards of higher education (FGOS VO) and the IMO STCW Convention (1978/95).
\end{abstract}


Keywords: organization of self-study, new technologies, requirements of federal educational standards of higher education (FGOS VO), STCW Convention, integration of general cultural and professional competences, distance learning.

Модернизация образования охватывает разные его сферы, в том числе и высшее образование, включая в вопросы комплексной организации учебного процесса и организацию самостоятельной работы студентов в вузе.

Об организации самостоятельной работы студентов вуза можно говорить, определив, прежде всего, понятие самостоятельная работа.

Не вдаваясь в дидактические и методологические подробности организации учебного процесса, можно утверждать, что он сводится к обучению студентов преподавателем, с одной стороны, и к приобретению знаний, умений и навыков самим студентом, с другой стороны. Задача учебного заведения и, соответственно, преподавателя - организовать учебный процесс таким образом, чтобы повысить эффективность обучения студента. Методические приёмы обучения включают как контактную работу (в аудитории, с преподавателем), так и неконтактную, т.е. обучение студента в отсутствие преподавателя). Логично назвать второй вид работы самостоятельной, но ведь и в аудитории, в присутствии преподавателя студенты могут выполнять работу самостоятельно, но под контролем преподавателя. Таким образом, можно выделить два вида самостоятельной работы: в аудитории и вне аудитории. Т. е. определение понятия самостоятельная работа автор рассматривает примерно так же, как и Н.М. Мекеко, квалифицируя её в зависимости от места её выполнения.

Традиционно в отечественной высшей школе предлагаются две формы обучения: очная и заочная.

При очной форме обучения, в соответствии с программой обучения и фондом оценочных средств, преподаватель определяет задания для аудиторной и внеаудиторной самостоятельной работы, а также виды её контроля в аудитории. Таким образом, организация самостоятельной работы преподавателем не представляет больших сложностей. 
В соответствии с федеральным государственным стандартом высшего профессионального образования (ФГОС ВПО) третьего поколения, на дисциплину «Иностранный язык» выделяется 340 часов (170- на практические занятия, 170 - на самостоятельную работу). При заочной форме обучения всего до 10\% от предусмотренных ФГОС учебных часов приходится на контактную работу (во время сессии), а также на контроль усвоенного учебного материала (зачёт/экзамен), о чём также говорит Н.М. Мекеко в своей статье «Новые технологии в обучении иностранным языкам студентов заочных отделений неязыковых вузов».

Безусловно, что только правильная организация самостоятельной работы преподавателем повысит эффективность обучения студентов.

Так как же правильно её организовать? Какими критериями руководствоваться? Какие методические инструменты применять?

Формирование профессиональной компетентности будущего специалиста эффективно реализуется в рамках компетентностного подхода, который представляет собой совокупность общих принципов определения цели и задач профессиональной подготовки, отбора содержания образования, организации образовательного процесса и оценки его результатов.

Требования ФГОС ВПО, рабочих программ и фондов оценочных средств имеют цель должным образом организовать учебный процесс для успешного освоения учебного материала студентами.

Грамотное распределение учебного материала по семестрам, эффективное планирование - залог успеха.

Обязательное ознакомление студентов с содержанием курса и методическими приёмами работы с учебным материалом, ссылками на учебную литературу и наличием ее в информационной среде - непреложное требование.

Обучение студентов приемам повышения внутренней мотивации при выполнении самостоятельной работы также обязательно. Как показывает практика, студентам заочного отделения трудно организовать своё учебное и рабочее время, и нельзя полностью полагаться на их сознательность и понимание необходимости изучения учебного материала. В качестве примера, можно обратиться 
к технике задавания себе вопросов по той или иной учебной теме, которая соответственно будет мотивировать студентов на поиск ответов в разных источниках, не только в учебной литературе.

Внешняя мотивация в виде экзаменационных требований также будет способствовать более эффективному освоению учебного материала.

Поскольку подготовка специалистов в морском вузе регламентируется как ФГОС ВПО, так и конвенцией ПДНВ (STCW78/95) в области владения профессиональным английским языком, который принят Международной Морской Организацией (IMO) в качестве международного рабочего языка на море, то вопрос разумной интеграции общекультурных и профессиональных компетенций в учебном процессе имеет немаловажное значение, что реализуется при составлении рабочей программы.

В области организации самостоятельной работы в аудитории и вне аудитории компетентностный подход имеет определенные отличия в части выбора технологий обучения.

Так, при контактной работе со студентами заочного отделения во время сессии наиболее приемлемы когнитивно-ориентированные технологии, т.к. включают в себя методы учебного диалога и учебной дискуссии, проблемное обучение, контекстное обучение.

Организация внеаудиторной самостоятельной работы на заочном отделении предполагает использование других технологий обучения, нацеленных на оценку сформированности компетенции.

При наличии новых технических и информационно-технологических возможностей, в частности, интернет-ресурсов, виртуальной обучающей среды на платформе Moodle и др., представляется целесообразным использовать их при организации самостоятельной работы студентов. Программное обеспечение на базе платформы Moodle с несложным для пользователя интерфейсом позволяет создавать и управлять дистанционным учебным курсом без специальной технической поддержки. 
Практическая задача преподавателя заключается в тщательном изучении своего учебного курса, постановке соответствующих задач обучения для определенных групп студентов, формы контроля и оценки и, с учетом своего педагогического опыта, в выборе тех инструментов дистанционного обучения, которые были бы наиболее эффективны не только в выполнении задачи обучения, но и в плане рационального использования своего времени и опыта.

Ознакомление с возможностями платформы Moodle для создания и использования дистанционных / электронных курсов по профессиональному английскому языку показывает, что инструменты, которые предлагает система, требуют технической доработки, поскольку не в полной мере отвечают ожиданиям качественной подготовки студентов.

Автор статьи «Новые технологии в обучении иностранным языкам студентов заочного отделения неязыковых вузов» М.Н. Мекеко предлагает после введения глоссария и текстов использовать обучающие тестовые задания в системе, которая сама контролирует и подсчитывает процент правильных ответов. Предполагается, что такой вид самостоятельной работы сократит время преподавателя на контроль задания, а также сформирует требуемые компетенции студента. Отчасти это соответствует действительности, но только отчасти. При обучении студентов иностранному языку (в нашем случае, английскому) виды заданий определяются такими видами речевой деятельности, как аудирование, говорение, чтение, письмо. Если чтение и письмо система может проконтролировать, то контроль аудирования и говорения невозможно провести без участия преподавателя, следовательно, рабочее время преподавателя не сокращается, а увеличивается, т.к. с каждым студентом необходимо общаться в режиме онлайн или офлайн во время его самостоятельной подготовки. Что касается обучающих тестовых заданий, то они не являются тренировочными упражнениями, которые формируют навык, т.е. нарушается традиционная технологическая обучающая цепочка: ознакомление с новым материалом, активизация, закрепление, контроль. Какого качества хлеб вы получите, если нарушите технологию приготовления? Разумеется, нельзя проводить такое прямое сравнение с качеством 
обучения студентов. Несомненно, новый вид задания образует новые нейронные связи в мозге обучающихся, но будут ли они способствовать более успешному формированию требуемых компетенций? На этот вопрос ответит время.

Для реализации идеи применения инструментов электронного дистанционного обучения в самостоятельной работе студентов заочного отделения следующие факторы имеют решающее значение:

- наличие в вузе соответствующей обучающей платформы с соответствующими обучающими программами с качественной технической поддержкой;

- наличие методической поддержки при создании дистанционного учебного курса;

- наличие в вузе стратегии по дистанционному обучению;

- наличие, в достаточной степени, соответствующего информационно-технологического оборудования для студентов;

- необходимо чёткое понимание, в создании какого курса преподаватель будет принимать участие, и точное определение его роли;

- руководству вуза необходимо понимать, что использование новых технологий в процессе обучения изменяет вид учебной нагрузки преподавателя, ни в коей мере не уменьшая её;

- при составлении индивидуального плана работы преподавателя из учебно-методической работы по созданию и управлению дистанционными курсами следует относить к учебной работе управление дистанционными курсами с соответствующим учетом рабочего времени;

Без учета каких-либо из этих факторов с использованием новых технологий неизбежно возникнут трудности, и об эффективности обучения, формировании необходимых компетенций у студентов заочного отделения можно будет говорить только в сослагательном наклонении.

Таким образом, предметом обсуждения становится вопрос разумного применения как традиционных средств обучения, так и новых информационно-технологических в самостоятельной работе при обучении студентов заочного отделения неязыкового вуза иностранному языку. 


\section{Сиисок литературы}

1. Князева О.Г. Компетентностный подход в профессиональном образовании в условиях реализации ФГОС СПО // Проблемы и перспективы развития образования: Материалы VI междунар. науч. конф. (г. Пермь, апрель 2015 г.). - Пермь: Меркурий, 2015. - с. 236-237 [Электронный ресурс]. - Режим доступа: http://moluch.ru/cof/ped/archive/149/7683/

2. Лебедев О.Е. Компетентностный подход в образовании // Школьные технологии. -2004 . - №5. - С. 3.

3. Мазилов В.А. Совершенствование высшего профессионального образования: методологические проблемы компетентностного подхода // Психология образования в XXI веке: теория и практика. Портал психологических изданий PsyJournals.ru [Электронный pecypc]. Режим доступа: http://psyjournals.ru/education21/issue/54094_full.shtml

4. Мекеко М.Н. Новые технологии в обучении иностранным языкам студентов заочного отделения неязыковых вузов // Вестник РУДН. - 2007. - №4 [Электронный ресурс].- Режим доступа: https://cyberleninka.ru/article/v/novyetehnologii-v-obuchenii-inostrannym-yazykam-studentov-zaochnyh-otdeleniyneyazykovyh-vuzov

5. Мекеко М.Н. Организация самостоятельной работы и контроля при обучении иностранному языку студентов заочного отделения // Вестник РУДН. - 2007. - №3 [Электронный pecypc]. - Режим доступа: https://cyberleninka.ru/article/v/organizatsiya-samostoyatelnoy-raboty-i-kontrolyapri-obuchenii-ino-strannomu-yazyku-studentov-zaochnogo-otdeleniya

6. Минаева И.Д. Методические проблемы обучения английскому языку курсантов морского вуза в рамках компетентностного подхода // Наука, образование, общество: тенденции и перспективы развития: Материалы X Междунар.науч.-практ. конф. (Чебоксары, 21 мая 2018 г.) / Редкол.: О.Н. Широков [и др.]. - Чебоксары: ЦНС «Интерактив плюс», 2018. - С. 81.

7. Мите Л.В. Самостоятельная работа - основное звено в системе дистанционного обучения // Проблемы высшего образования. - С. 221 [Электронный 
pecypc]. - Режим доступа: https://cyberleninka.ru/article/v/samostoyatelnaya-rabotaosnovnoe-zveno-v-sisteme-distantsionnogo-obucheniya

8. Oxford Learning: Best methods of self-study for students [Электронный peсурс]. - Режим доступа: https://www.oxfordlearning.com/best-methods-of-selfstudy-for-students/

9. Teaching and Learning in Higher Education by Heather Fry, Steve Ketteridge, Stephanie Marshall [Электронный pecypc].- Режим доступа: http://biblioteca.ucv.cl/site/colecciones/manuales_u/A\%20Handbook\%20for\%20Tea ching\%20and\%20Learning\%20in\%20Higher\%20Education\%20Enhancing\%20aca

\section{References}

1. Knyazeva O.G. Competence approach in professional education in the terms of realizing federal educational standards of high professional education // Problems and perspectives of education development: Materials of VI international scientific conference (Perm, April 2015). - Perm: Mercury, 2015. - P .236-237 [Electronic resource]. - Access: http://moluch.ru/cof/ped/archive/149/7683/

2. Lebedev O.E. Competence approach in education // School technologies. - 2004. - №5. - P. 3.

3. Mazilov V.A. Development of higher professional education: methodological problems of competence approach // Portal of psychological publications PsyJournals.ru [Electronic resource]. http://psyjournals.ru/education21/issue/54094_full.shtml

4. Mekeko M.N. New technologies in teaching foreign languages part-time students of non-linguistic universities // RUDN bulletin. - 2007. - №4 [Electronic resource]. - Access: https://cyberleninka.ru/article/v/novye-tehnologii-v-obucheniiinostrannym-yazykam-studentov-zaochnyh-otdeleniy-neyazykovyh-vuzov

5. Mekeko M.N. Organization of self-study and control in teaching part-time students a foreign language // RUDN bulletin. - 2007. - №3 [Electronic resource]. - Access: https://cyberleninka.ru/article/v/organizatsiya-samostoyatelnoyraboty-i-kontrolya-pri-obuchenii-ino-strannomu-yazyku-studentov-zaochnogootdeleniya 
6. Minaeva I.D. Methodological challenges and competence-based approach in teaching English at the maritime university // Science, education, society: development trends and perspectives: Materials of X international scientific and practical conference (Cheboksary, May, 21, 2018) / Editorial board: O.N. Shirokov [and others]. - Cheboksary: CNC 'Interactiv plus', 2018. - P. 81.

7. Mite L.V. Self-study as an integral part of distance learning // Problems of higher education. - $\quad$ P. 221 [Electronic resource]. - Access: https://cyberleninka.ru/article/v/samostoyatelnaya-rabota-osnovnoe-zveno-v-sistemedistantsionnogo-obucheniya

8. Oxford Learning: Best methods of self-study for students [Electronic resource]. - Access: https://www.oxfordlearning.com/best-methods-of-self-study-forstudents/

9. Teaching and Learning in Higher Education by Heather Fry, Steve Ketteridge, Stephanie Marshall [Electronic resource]. - $A c c e s s:$ http://biblioteca.ucv.cl/site/colecciones/manuales_u/A\%20Handbook\%20for\%20Tea ching\%20and\%20Learning\%20in\%20Higher\%20Education\%20Enhancing\%20aca

Минаева Ирина Дмитриевна - соискатель, старший преподаватель ФГБОУ ВО «Государственный университет морского и речного флота им. адмирала С.О. Макарова», Россия, Санкт-Петербург.

Minaeva Irina Dmitrievna - applicant, senior teacher at the Admiral Makarov State University of Maritime and Inland Shipping (SUMIS), Russia, Saint Petersburg. 